\title{
Prevalence of Inadequacy Intake for Older People: The Use of National Cancer Institute (NCI) Method
}

\author{
Luciana Bronzi de Souza $^{1}$, José Eduardo Corrente ${ }^{2}$, Silvia Justina Papini ${ }^{3}$ \\ ${ }^{1}$ Public Health Department, Botucatu School of Medicine, São Paulo State University, Botucatu, Brazil; ${ }^{2}$ Biostatistics Department, \\ Bioscience Institute, São Paulo State University, Botucatu, Brazil; ${ }^{3}$ Nursing Department, Botucatu School of Medicine, São Paulo \\ State University, Botucatu, Brazil. \\ Email: luciana.bronzi@gmail.com, jecorren@ibb.unesp.br, spberto@fmb.unesp.br
}

Received June $19^{\text {th }}, 2013$; revised July $19^{\text {th }}, 2013$; accepted July $26^{\text {th }}, 2013$

Copyright (c) 2013 Luciana Bronzi de Souza et al. This is an open access article distributed under the Creative Commons Attribution License, which permits unrestricted use, distribution, and reproduction in any medium, provided the original work is properly cited.

\begin{abstract}
A purpose of dietary assessment is to evaluate the dietary intake of a group or a population. In Brazil few studies have been carried out to identify dietary intake of older people population. Then, the aim of this work is to estimate the distribution as well as estimate the prevalence of inadequacy of the usual intake in a representative sample of older population from Botucatu city, São Paulo, applying the NCI method. A sample of 365 older was used and some instruments to evaluate quality of life, activities of daily living and instrumental of daily living were applied as well as three 24-hour recalls. Data from the recalls were transformed in consumption of macro and micronutrients using NDSR software and were analyzed using NCI method in order to estimate the inadequacy prevalence. The energy and macronutrients intake of the studied population agree with their needs, however, the consumption of minerals and vitamins were below the recommendation even after including the covariates. This can reflects a monotone intake that is characteristic of this age and this inadequateness can be a serious public health problem that can carry on development of chronic diseases. Also, it is important to highlight that NCI method provides a good estimate of the usual intake.
\end{abstract}

Keywords: Older People; NCI Method; Prevalence of Inadequacy; Usual Intake

\section{Introduction}

A common purpose of dietary assessment is to evaluate the dietary intake of a group or population in relation to some standard, with respect to both nutrient adequacy and the prevention of chronic disease [1].

There are several methods to measure the intake of nutrients and foods. The more commonly used method is 24-hour recall. The main point is that one recall does not estimate the usual intake, once the central characteristic of the diet is the daily variability (Willett, 1998). Factors as day of the week, seasonality among others contribute for this variability. Therefore, it is necessary to use statistical methods to estimate usual dietary intake in order to remove the within-person variability [2].

Several researches have been carried out in developed countries in order to identify the usual intake for older people [3-7]. However, in Latin America, particularly in Brazil, this sort of investigation is rare [8,9]. In this way, it is important to know the feed situation of the older people in Brazil and the use of statistical techniques can help to estimate the more correct prevalence of usual intake. In this way, some statistical methods have been developed in order to remove within-person variability fitting a measurement error model and the prevalence of inadequacy intake is calculated from a given standard for several nutrients according to Estimate Average Recommendation (EAR) or Adequate Intake (AI). Such methods are four: National Research (NR), Iowa State University (ISU), Iowa State University for Foods (ISUF), Best Power (BP) and National Cancer Institute (NCI). The frames of these methods are the same and differences between the methods arise from different assumptions about the measurement characteristics of 24-hour recalls [1]. The main point is the NCI method that leads a substantial improvement over the other to estimate the distribution of usual intake. Extensions of this model have also been proposed including the episodically consume of foods [10] (Kipnis, 2009).

Then, the aim of this work is to estimate the distribution as well as the prevalence of inadequate intake in a representative sample of older people from the city of Botucatu, São Paulo, Brazil, applying the NCI method. 


\section{Metodology}

This is a cross-sectional study to evaluate de adequate intake and the nutritional status for older people.

It was used a representative sample of older people from the city of Botucatu, São Paulo, Brazil, obtained for a quality of life study. The sample size was calculated considering an unknown prevalence of quality of life (50\%), error margin of 5\% and confidence level of $95 \%$ totalizing 365 older people chosen randomly form the population. In case of refuse or death, a new subject was drawn.

A sociodemographic, morbidities, Flanagan quality of life scale and functional capacity scales (Activities of Daily Living (ADL) developed by Katz and Instrumental Activities of Daily Living (IADL) developed by Brody and Lawnton) questionnaires were applied. The nutritional data were obtained applying three 24-hour recalls in different and non consecutive days of the week, one being at weekend. The 24-hour recall was compounded by three questions: 1) meal and time; 2) food intake; 3) quantity-household measure. The data were collected from January/2010 to August/2011. The application of 24-hour recall was made in a standard way using the USDA five-step multiple-pass method for dietary recall [11].

The obtained data from the three 24-hour recalls was converted in intake of nutrients using the Nutrition Data System (NDSR). Energy, protein, carbohydrate, fiber, total fat, mono and polisaturated was obtained as macronutrients and vitamins A, B1, B2, B3, B6, C, E, potassium, phosphorus, folate, iron, pantothenic acid, calcium, magnesium, selenium and zinc as a micronutrients.

Descriptive analysis was initially made with sociodemographic, morbidities and intake data. The distribution of the intake was made fitting a measurement error model and the application of the NCI method using MIXTRAN and DISTRIB routines developed in SAS for windows language [2]. In order to estimate the prevalence of inadequate intake, it was use EAR or AI as a cutoff adjusted for possible confounding variables. The prevalence was also obtained calculating the empirical distributions. Comparison between the prevalences obtained by NCI and empirical method was made using proportion differences test. The significant level was fixed in $5 \%$ or the correspondent p-value. All the procedures were according the Ethics Committee of the Botucatu School of Medicine.

\section{Results}

According to the data collected, it was observed that $62.6 \%$ of the older was female and $37.4 \%$ was male. Table 1 presents the demographic aspects for this population. The general mean age was $72.11(\mathrm{SD}=7.35)$ years, being 72.38 (SD $=7.45$ ) years for female and 71.57 (SD $=7.30)$ year for male $(p=0.1461)$.

The prevalence of the main referred pathologies was:

Table 1. Distribution of the demographic aspects of the older people by gender. Botucatu, 2011.

\begin{tabular}{|c|c|c|c|c|c|}
\hline & Female $(n=226)$ & & Male $(n=135)$ & & p-valor \\
\hline Age & $72.10 \pm 7.35$ & & $71.57 \pm 7.30$ & & 0.1461 \\
\hline \multirow[t]{2}{*}{ Income (US\$) } & $608.10 \pm 774.16$ & & $903.86 \pm 1002.46$ & & $\mathrm{p}<0.0001$ \\
\hline & $\mathrm{n}$ & $\mathrm{p}$ & $\mathrm{n}$ & $\mathrm{p}$ & \\
\hline Married & 101 & 44.69 & 109 & 80.74 & $\mathrm{p}<0.0001$ \\
\hline Single & 23 & 10.18 & 8 & 5.93 & \\
\hline Widow & 91 & 40.27 & 13 & 9.63 & \\
\hline Separetd & 5 & 2.21 & 2 & 1.47 & \\
\hline Ilitterate & 45 & 19.91 & 10 & 8.09 & $\mathrm{p}=0.0004$ \\
\hline Elementary school & 142 & 62.83 & 80 & 59.26 & \\
\hline Secondary school & 19 & 8.41 & 20 & 14.81 & \\
\hline Graduate school & 20 & 8.85 & 25 & 18.51 & \\
\hline \multicolumn{6}{|l|}{ Labor situation } \\
\hline Yes & 16 & 7.08 & 23 & 17.04 & $p=0.0032$ \\
\hline No & 210 & 92.92 & 112 & 82.96 & \\
\hline \multicolumn{6}{|l|}{ Rretired } \\
\hline Yes & 189 & 83.63 & 125 & 92.59 & $\mathrm{p}<0.0001$ \\
\hline No & 37 & 16.37 & 10 & 7.41 & \\
\hline
\end{tabular}


hypertension (44.68\%), diabetes mellitus (28.81\%), hypercholesterolemia (15.51\%), heart disease (7.76\%), osteoporosis (8.59\%) and thyroid disorders (7.20\%). Related to the functional capacity, it was found that $89.9 \%$ and $67.6 \%$ of the older adults were totally independent for ADL and IADL, respectively.

The intake data from the 24-hour recall obtained from the NDSR software and are presented in Table 1 stratified by gender. As the distribution of the data were asymmetric, the comparison between sex was made us- ing Wilcoxon test.

As we found significant differences in most nutrients consumed by the older considering male and female, inadequate intake prevalence was obtained separated by gender. Tables $\mathbf{2}$ and $\mathbf{3}$ presents the estimated prevalence calculated by NCI and empirical method. Significance was calculated using difference proportion test.

\section{Discussion}

This proposed paper aimed to estimate usual intake of

Table 2. Comparison of the intake between gender for macro and micronutrients for older adults. Botucatu, 2011.

\begin{tabular}{|c|c|c|c|}
\hline & Male & Female & \\
\hline Nutrient & Median (Q1 - Q3) & Median (Q1 - Q3) & p-valor \\
\hline Energy (kcal) & 2044.27 (570.92 - 2522.19) & $1663.48(1295.93-2142.48)$ & $<0.0001$ \\
\hline Total fat (g) & 71.68 (50.51 - 97.36) & 57.04 (39.95 - 84.50) & $<0.0001$ \\
\hline Carbohydrate (g) & $238.52(174.62$ - 304.32) & $203.11(162.73-270.17)$ & $<0.0001$ \\
\hline Protein (g) & $94.24(67.63$ - 119.15) & 73.02 (53.40 - 98.16) & $<0.0001$ \\
\hline Cholesterol (mg) & $233.16(144.29$ - 395.90) & $201.24(121.65$ - 297.55) & $<0.0001$ \\
\hline Saturated fat (g) & $22.80(14.58-31.75)$ & $18.52(11.86$ - 26.94) & $<0.0001$ \\
\hline Monounsaturated fat (g) & $25.09(16.29$ - 34.64) & $18.84(12.47$ - 28.25) & $<0.0001$ \\
\hline Polyunsaturated fat (g) & $17.24(11.58$ - 23.84) & 13.77 (9.55 - 19.92) & $<0.0001$ \\
\hline Fiber (g) & $18.78(12.35-25.50)$ & $16.55(11.89$ - 23.01) & 0.0064 \\
\hline Percentage of fat & $32.21(26.11-38.22)$ & $31.28(25.10$ - 37.44) & 0.1729 \\
\hline Percentage of carbohydrate & 46.99 (40.94 - 54.92) & $50.03(42.67$ - 57.48) & 0.0002 \\
\hline Percentage of protein & $18.65(15.03-21.78)$ & 17.58 (14.09 - 21.33) & 0.0643 \\
\hline Vitamin A (mcg) & 713.22 (350.41 - 1218.22) & 756.86 (349.26 - 1330.65) & 0.2084 \\
\hline Vitamin D (mcg) & $3.64(2.10-5.56)$ & $3.40(2.02-5.18)$ & 0.2044 \\
\hline Vitamin E (mg) & $6.13(4.52-8.39)$ & $5.48(3.81-7.33)$ & 0.0002 \\
\hline Vitamin K (mcg) & $103.37(54.76-187.38)$ & 101.77 (52.35 - 168.25) & 0.3472 \\
\hline Vitamin C (mg) & $54.72(22.33$ - 134.09) & 54.08 (24.71 - 110.39) & 0.7843 \\
\hline Vitamin B1 (mg) & $1.53(1.19-2.01)$ & $1.34(0.99-1.78)$ & $<0.0001$ \\
\hline Vitamin B2 (mg) & $1.55(1.11-2.10)$ & $1.41(1.06-1.82)$ & 0.0023 \\
\hline Vitamin B3 (mg) & 20.60 (14.63 - 29.39) & 17.50 (11.91 - 24.85) & $<0.0001$ \\
\hline Panthotenic Acid (mg) & $5.00(3.75-6.15)$ & $4.44(3.39-5.67)$ & $<0.0001$ \\
\hline Vitamin B6 (mg) & $1.77(1.27-2.43)$ & $1.52(1.08-2.14)$ & $<0.0001$ \\
\hline Folate (mcg) & 399.81 (308.13 - 529.95) & $336.36(257.55-433.00)$ & $<0.0001$ \\
\hline Vitamin B12 (mcg) & $3.47(2.06-5.62)$ & $2.93(1.79-4.88)$ & 0.0098 \\
\hline Calcium (mg) & 637.66 (401.82 - 929.69) & $559.98(390.42$ - 837.05) & 0.0314 \\
\hline Phosphorus (mg) & 1174.11 (852.61 - 1551.09) & 1011.75 (749.01 - 1308.05) & $<0.0001$ \\
\hline Magnesium (mg) & $276.55(206.06-350.66)$ & 227.18 (174.92 - 293.95) & $<0.0001$ \\
\hline Iron (mg) & $15.14(10.78-19.88)$ & $12.02(8.88-16.10)$ & $<0.0001$ \\
\hline Zinc (mg) & 11.99 (8.58 - 15.73) & 9.60 (6.89 - 12.93) & $<0.0001$ \\
\hline Selenium (mcg) & $126.00(92.23-173.43)$ & 102.59 (76.19 - 143.12) & $<0.0001$ \\
\hline Total Vitamin A (mcg) & $515.45(310.93$ - 845.12) & $520.30(288.80-846.30)$ & 0.9343 \\
\hline Manganese (mg) & $3.12(2.02-4.14)$ & $2.57(1.95-3.68)$ & 0.0015 \\
\hline
\end{tabular}


Table 3. Estimate prevalence of inadequate intake of nutrients for older people by gender using NCI and empirical method (in parenthesis). Botucatu, 2010.

\begin{tabular}{|c|c|c|c|c|}
\hline & Female & & Male & \\
\hline Micronutrients & Recomendation & Inadequate & Recomendation & Inadequate \\
\hline Vitamin A (mcg) & 625 & $18.2(3.0)^{*}$ & 500 & $9.2(8.2)$ \\
\hline Vitamin D (mcg) AI & 15 & $98.5(96.3)$ & 15 & $99.6(94.1)^{*}$ \\
\hline Vitamin E total (mg) & 12 & $97.4(94.4)$ & 12 & $99.7(94.6)^{*}$ \\
\hline Vitamin K (mcg) AI & 120 & $39.8(44.8)^{*}$ & 90 & $20.6(54.8)^{*}$ \\
\hline Vitamin C (mg) & 75 & $35.3(53.2)^{*}$ & 60 & $28.5(58.8)^{*}$ \\
\hline Vitamin B1 (mg) & 1 & $2.1(17.2)^{*}$ & 0.9 & $0.4(12.7)^{*}$ \\
\hline Vitamin B2 (mg) & 0.9 & $8.1(14.9)^{*}$ & 1.1 & $2.5(24.9)^{*}$ \\
\hline Vitamin B3 (mg) & 12 & $0.6(21.0)^{*}$ & 11 & $0.5(12.1)^{*}$ \\
\hline Panthotenic Acid (mg) AI & 5 & $41.6(63.8)^{*}$ & 5 & $64.3(50.0)^{*}$ \\
\hline Vitamin B6 (mg) & 1.4 & $9.8(37.2)^{*}$ & 1.3 & $16.5(29.4)^{*}$ \\
\hline Total Folate (mcg) & 320 & $16.9(44.3)^{*}$ & 320 & $29.7(27.7)$ \\
\hline Vitamin B12 (mcg) & 2 & $1.0(30.1)^{*}$ & 2 & $0.0(24.0)^{*}$ \\
\hline Calcium (mg) AI & 1200 & 80.9 (85.9) & 1200 & $91.5(79.4)^{*}$ \\
\hline Phosphorus (mg) & 580 & $0.5(12.9)^{*}$ & 580 & $0.9(7.3)^{*}$ \\
\hline Magnesium (mg) & 350 & $73.9(65.3)^{*}$ & 265 & $66.8(74.9)$ \\
\hline Iron (mg) & 6 & $0.3(2.7)^{*}$ & 5 & $0.0(3.7)^{*}$ \\
\hline Zinc (mg) & 9.4 & $13.3(24.2)^{*}$ & 6.8 & $4.0(31.9)^{*}$ \\
\hline Selenium (mcg) & 45 & $0.0(5.2)^{*}$ & 45 & $0.0(2.54)$ \\
\hline Sodium (g) AI & 1.3 & $0.0(5.6)^{*}$ & 1.3 & $0.0(2.54)$ \\
\hline Potassium (g) AI & 4.7 & $94.1(96.5)^{*}$ & 4.7 & $99.9(92.4)^{*}$ \\
\hline Manganese (g) AI & 1.8 & $6.7(20.7)^{*}$ & 1.8 & $12.3(18.1)$ \\
\hline
\end{tabular}

${ }^{*} \mathrm{p}<0.05$.

nutrients for older people using NCI method for older people. According to our knowledge this is the first work in Brazil to calculate the prevalence of inadequacy for older people using the method that take account the within-variance and covariates for intake data and for older people.

According to Table 1, most of the older people were female, married, with elementary school and retired. The intake data were presented in Table 2 in median and quantiles, once most of them presented distribution totally asymmetric and differences were found for man and women. It can be observed that the almost consumption of macros and micronutrients differs by gender and the consumption form males are greater than females. Then, the analysis was carried out separately for men and women.

The energy and macronutrients intake of the studied population agree with their needs, however the consumption of minerals and vitamins were below the recommendation even after including the covariates (Tables 3 and 4). This can reflects a monotone intake that is characteristic of this age. This inadequateness can be a serious public health problem once this group is susceptible to nutritional problems and the increasing of chronic diseases. Despite of these findings in our study, one point to think about is: how precise is the estimate of inadequate intake? Using a difference of proportion test, we found that several prevalences estimate of the usual intake differs using NCI and empirical method. This is something expected once the empirical method does not take in account the within-person variability. Even though, the use of covariates seems minimize the effect of this variability, once we found a lower differences. Unfortunately we cannot explain why this happens, once 
Table 4. Estimate prevalence of inadequate intake of nutrients for older people by gender using NCI and empirical method (in parenthesis) adjusted by age, marital status, schooling ADL an IADL. Botucatu, 2010.

\begin{tabular}{|c|c|c|c|c|}
\hline & Male & & Female & \\
\hline Micronutrients & Recomendation & Inadequacy & Recomendation & Inadequacy \\
\hline Vitamin A (mcg) & 625 & $24.9(7.58)^{*}$ & 500 & $20.8(3.21)^{*}$ \\
\hline Vitamin D (mcg) AI & 15 & $98.5(96.07)$ & 15 & $99.7(97.47)$ \\
\hline Total Vitamina E (mg) & 12 & $97.2(82.87)^{*}$ & 12 & $99.7(81.59)^{*}$ \\
\hline Vitamin K (mcg) AI & 120 & 44.7 (48.03) & 90 & $29.4(40.54)^{*}$ \\
\hline Vitamin C (mg) & 75 & $41.7(53.93)^{*}$ & 60 & $36.2(47.97)^{*}$ \\
\hline Vitamin B1 (mg) & 1 & $10.6(11.80)$ & 0.9 & $11.9(15.37)$ \\
\hline Vitamin B2 (mg) & 1.1 & 16.5 (22.19) & 0.9 & $14.3(13.34)$ \\
\hline Vitamin B3 (mg) & 12 & $8.9(10.67)$ & 11 & $11.9(20.10)$ \\
\hline Panthotenic Acid (mg) AI & 5 & $41.6(43.26)$ & 5 & $69.3(57.94)$ \\
\hline Vitamin B6 (mg) & 1.4 & $18.2(26.69)^{*}$ & 1.3 & $26.4(33.11)$ \\
\hline Folate (mcg) & 320 & $23.9(24.44)$ & 320 & $36.0(38.68)$ \\
\hline Vitamin B12 (mcg) & 2 & $8.85(22.19)^{*}$ & 2 & $11.1(28.38)^{*}$ \\
\hline Calcium (mg) AI & 1200 & 82.5 (79.49) & 1200 & $92.2(84.97)$ \\
\hline Phosphorus (mg) & 580 & $0.5(6.46)^{*}$ & 580 & $12.4(11.82)$ \\
\hline Magnesium (mg) & 350 & $75.7(68.82)$ & 265 & $70.3(58.61)^{*}$ \\
\hline Iron (mg) & 6 & $8.37(2.81)^{*}$ & 5 & $9.70(2.20)^{*}$ \\
\hline Zinc (mg) & 9.4 & $20.5(28.37)^{*}$ & 6.8 & 14.8 (21.79) \\
\hline Selenium (mcg) & 45 & $7.48(2.25)^{*}$ & 45 & $9.04(4.22)$ \\
\hline Sodium (g) AI & 1.3 & $8.10(0.00)^{*}$ & 1.3 & $11.7(0.00)^{*}$ \\
\hline Potassium (g) AI & 4.7 & $94.4(0.00)^{*}$ & 4.7 & $99.9(0.00)^{*}$ \\
\hline Manganese (g) AI & 1.8 & $14.1(20.7)^{*}$ & 1.8 & $22.5(18.1)$ \\
\hline
\end{tabular}

${ }^{*} \mathrm{p}<0.05$.

it is not possible to include covariates in the empirical methods.

The NCI method proposes to estimate the distribution of the usual intake for food consumed episodically but it can also be used for nutrients correcting by the withinperson variance. The routines to calculate this distribution are available in SAS language and they can be obtained in the site of NCI. The advantage of this method is the possibility of using covariates that can be influence the distribution of usual intake. The main problem to estimate the inadequacy prevalence is that we use the values of EAR's as a cutoff. This means that the distribution of true usual intake is normal and this didn't happen with the considered dataset. In order to normalize the data, a Box-Cox transformation is used for NCI method but not always the transformation is successful.

Tables 2 and $\mathbf{3}$ show the inadequacy prevalence ob- tained by NCI and empirical method for raw and adjusted data. These results show a little difference when we adjust for age, marital status, schooling, ADL and IADL. Most of the nutrients had high inadequate prevalence for both cases and both methods. Some differences can be observed between NCI and empirical methods, once the empirical method does not take the within-variance in account. As the distribution of the intake data were so asymmetric, the empirical distribution cannot give a reliable estimate of the prevalence of inadequacy intake.

It is difficult to find in the available literature comparisons among methods to estimate the distribution of usual intake. Generally, authors use the available methods without analyze carefully the obtained results and no questions are raised about the validity of the used method.

One of the papers compares four methods to estimate 
usual distribution intake: National Cancer Institue (NCI), Iowa State University (ISU), Multiple Source Method (MSM) and Statistical Program for Ade-adjusted Dietary Assessment (SPADE) [12]. According to the authors, differences were observed in NCI method mainly when the distribution is highly skewed, as it was observed in this present work. The authors concluded these four methods provide good estimates of usual intake, but care is need for high within-variance, highly skewed distribution and small sample size.

Another proposed method to estimate usual intake take in account an age-dependent model that improve the precision of the estimates and provide advantages above the current methods [13]. In case of older people, age can have some influence in the distribution of usual intake but, in our data, only schooling showed significance for some nutrients.

One suggestion for future studies is the use of methods specifically developed for asymmetric distributions using the same model with measurement errors like the NCI method.

\section{Conclusion}

In conclusion and according to the obtained results in this study, it was found a low consumption of vitamins and minerals for this population. Also, It is important to highlight that all available methods to estimate usual intake are good and give reasonable results but care is always need when analyses are made using these methods. For this is important to know the particular features in each one.

\section{Acknowledgements}

The authors would like to thank to São Paulo Foundation Research (FAPESP-Process no. 2008/10261-8) and National Counsel of Technological and Scientific Development (CNPq Process no. 301197/2011-3) for the financial support.

\section{REFERENCES}

[1] K. W. Dodd, P. M. Guenther, L. S. Freedman, A. F. Subar, V. Kipnis, D. Midthune, J. A. Tooze and S. M. KrebsSmith, "Statistical Methods for Estimating Usual Intake of Nutrients and Foods: A Review of the Theory,” Journal of the American Dietetic Association, Vol. 106, No. 10, 2006, pp. 1640-1650. http://dx.doi.org/10.1016/j.jada.2006.07.011

[2] J. A. Tooze, D. Midthune, K. W. Dood, L. S. Freedman, S. M. Krebs-Smith, A. F. Subar, P. M. Guenther, R. J. Carroll and V. Kipnis, "A New Statistical Method for Estimating the Usual Intake of Episodically Consumed
Foods with Application to Their Distribution,” Journal of the American Dietetic Association, Vol. 106, No. 10, 2006, pp. 1575-1587. http://dx.doi.org/10.1016/j.jada.2006.07.003

[3] L. Davies and M. B. Holdsworth, "Nutrition and Health at Retirement Age in the United Kingdom," Human Nutrition. Applied Nutrition, Vol. 39, No. 5, 1985, pp. 315332.

[4] J. H. Hankin, "Development of a Diet History Questionnaire for Studies of Elder Persons,” The American Journal of Clinical Nutrition, Vol. 50, No. S5, 1989, pp. 11211127.

[5] B. K. Jacobsen and K. H. Bonna, "The Reproducibility of Dietary Data from a Self-Administered Questionnaire. The Tromso Study," International Journal of Epidemiology, Vol. 19, No. 2, 1990, pp. 349-353. http://dx.doi.org/10.1093/ije/19.2.349

[6] P. O’Hanlon and M. B. Kohrs, "Dietary Studies of Older Americans," The American Journal of Clinical Nutrition, Vol. 31, No. 7, 1978, pp. 1257-1269.

[7] L. Ruiz, "Promotion and Protections of the Adult Health in Latin America and Caribbean," Educacion Medica y Salud, Vol. 23, No. 1, 1989, pp. 87-100.

[8] A. Horwitz, "Guidelines for Food and Nutritional Aims for Aging,” Archivos Latinoamericanos de Nutrición, Vol. 38, No. 3, 1998, pp. 722-749.

[9] E. A. Perez, "Adult Health in Latin America: Real Situation and Perspectives," Educacion Medica y Salud, Vol. 23, No. 1, 1989, pp. 75-86.

[10] V. Kipnis, D. Midthune, D. W. Buckman, K. W. Dodd, P. M. Guenther, S. M. Krebs-Smith, A. F. Subar, J. A. Tooze, R. J. Carroll and L. S. Freedman, "Modeling Data with Excess Zeros and Measurement Error: Application to Evaluating Relationships between Episodically Consumed Foods and Health Outcomes,” Biometrics, Vol. 65, No. 4, 2009, pp. 1003-1010.

http://dx.doi.org/10.1111/j.1541-0420.2009.01223.x

[11] J. M. Conway, L. A. Ingwersen and A. J. Moshfegh, “Accuracy of Dietary Recall Using the USDA Five-Step Multiple-Pass Method in Men: An Observational Validation Study," Journal of the American Dietetic Association, Vol. 104, No. 4, 2004, pp. 595-603. http://dx.doi.org/10.1016/j.jada.2004.01.007

[12] O. W. Souverein, A. L. Dekkers, A. Geelen, J. Hwubrock, J. H. de Vries, M. C. Ockré, U. Harttig, H. Boeing and P. V. Veer, "Comparing Four Methods to Estimate Usual Intake Distribution," European Journal of Clinical Nutrition, Vol. 65, No. S1, 2011, pp. S92-S101.

http://dx.doi.org/10.1038/ejcn.2011.93

[13] P. M. C. M. Waijers, A. L. M. Dekkers, J. M. A. Boer, H. C. Boshuizen and C. T. M. van Rossum, "The Potential of AGE MODE, an Age-Dependent Model, to Estimate Usual Intakes and Prevalences of Inadequate Intakes in a Population,” The Journal of Nutrition, Vol. 136, No. 11, 2006, pp. 2916-2920. 